\title{
A África para crianças da educação infantil
}

\author{
Africa to kindergarten children \\ L'Afrique pour enfants de l'éducation infantile
}

Andréa Mesquita RAMPONE

Andréa Rigazzo MAIOLINO

\begin{abstract}
RESUMO
Depoimento sobre duas experiências que tiveram como objetivo apresentar a África para crianças da Educação Infantil a partir de um projeto que inclui uma breve apresentação do continente africano, uma discussão a cerca do tema e um trabalho artístico de desenho e pintura.
\end{abstract}

Palavras-chave: Educação Infantil, África, Projeto, Artes.

\section{ABSTRACT}

Report about two experiences with the goal to present Africa to children in kindergarten through a project with a briefing about African continent, a discussion about the subject and an artistic work of design and picture.

Index terms: Kindergarten, Africa, project, Arts.

\section{RÉSUMÉ}

Ce témoignage est sur deux expériences qui ont eu comme objectif présenter l'Éducation pour enfants, aux enfants de l'Afrique, à partir d'un projet qui présente une bréve présentation du continent africain, une discussion autour d'un sujet et un travail artistique de dessin et pinture.

Mots-clés: Éducation pour enfants, Afrique, Projet, Arts. 


\title{
Apresentação: “A África para crianças da educação infantil”"
}

Aproveitando o nosso ambiente de trabalho, escolas de educação infantil, e atendendo à solicitação da professora doutora Nilce da Silva em "espaço de criação" que freqüentamos no primeiro semestre de 2008, pensamos em uma maneira lúdica de apresentar a África aos nossos pequenos alunos.

Um tema que consideramos interessante e cativante para crianças de idades entre três a seis anos é "os animais que constituem a fauna do continente africano", já que as crianças costumam se encantar bastante com temas que incluem animais e natureza. A nossa atividade de intervenção se constituiu em:

1- Iniciamos a atividade em "roda de conversa" explicando um pouco sobre a África com a ajuda de materiais gráficos como revistas, fotos, desenhos. Propusemos uma discussão sobre o tema, para tentar colher dados e informações que eles apresentem e a partir disso, adicionar e enriquecer a conversa com novas informações.

2- Em seguida, propusemos montagem de um trabalho coletivo que envolvesse o que foi discutido anteriormente, registrando o que cada um mais gostou. Esse trabalho foi feito com colagem de recortes do material apresentado no começo da discussão e desenhos das próprias crianças.

\section{Atividade desenvolvida no Colégio Sagrado Coração de Jesus}

\author{
Por Andréa Rampone
}

Com a proposta de apresentar o aspecto fauna africana para crianças da Educação Infantil, escolhi a classe de crianças de cinco e seis anos do 
Colégio Sagrado Coração de Jesus localizado na zona Oeste de São Paulo. O colégio atende crianças de classe média desde Educação Infantil até Ensino Médio. É um colégio católico dirigido por freiras e tem mais de 70 anos de história. Para isto, fui muito bem recebida, tanto a coordenadora quanto a professora pareceram abertas ao tema. Entretanto não tive contato com a diretora.

Iniciei o meu trabalho fazendo uma "roda de conversa" com os alunos, apresentei-me e expliquei às crianças o que estava fazendo lá. Em seguida, deixei que eles se apresentassem e contassem para mim sobre os animais de que mais gostavam e sobre quais animais eles achavam que existiam na África. Porém percebi que as poucas respostas que obtive foram vagas e, portanto, achei melhor mostrar alguns dos materiais que havia levado.

Abri o mapa do mundo e deixei que eles olhassem um pouco, e, ao mesmo tempo, fizessem suas perguntas. Então, expliquei que aquele desenho era o mapa do mundo; mostrei os continentes, o Brasil, o estado de São Paulo, a cidade e alguns outros pontos importantes. Finalizei indicando no mapa para eles onde era a África e fornecendo algumas informações sobre o continente, dando maior ênfase em dados sobre a fauna, como, por exemplo, espécies presentes no continente.

Ao falar dos animais, exibi algumas fotos que havia levado, incluindo fotos do continente africano em geral, geografia, população, capitais, pontos turísticos, aldeias, praias, centros comerciais, etc.

Enquanto mostrava as fotos, íamos conversando sobre as imagens e as crianças expunham suas opiniões e comentários. Todos da turma estavam bastante interessados e envolvidos, contavam tudo que sabiam sobre os animais a respeito dos quais estávamos conversando. Muitos contavam que 
já haviam visto alguns deles no zoológico ou na televisão. Alguns faziam associações com filmes, músicas ou histórias que haviam escutado em algum lugar.

O que surpeendeu muitos deles era o fato de existir pessoas que conviviam com alguns dos animais selvagens, de forma respeitosa, e sem grades de proteção, correntes ou armas de fogo. Quanto às tribos, eles as comparavam às tribos indígenas brasileiras, porém também não pareciam saber muito sobre isso. Apresentei também alguns aspectos culturais como música, costumes e culinária. Aproveitei para lembrá-los das influências africanas na cultura brasileira, como por exemplo, a capoeira, que muitos deles conheciam.

Depois de toda esta conversa, música e fotos, nós executamos um trabalho em grupo de registro do que havia sido falado. Ofereci a eles revistas, tesouras, cola, canetinhas, giz e lápis coloridos para que fizéssemos juntos um trabalho coletivo num único papel (bem grande) em que cada um pudesse registrar as coisas das quais mais gostaram.

Eles desenharam os animais, aldeias, plantas, pessoas e cidades. Para tanto, também utilizaram recortes das revistas para incrementar o trabalho. Durante o trabalho em equipe, as crianças estavam muito animadas e montavam histórias sobre o que estavam desenhando, conversando sobre o que haviam aprendido.

A professora da sala gostou muito da atividade realizada e disse que, embora considere este tema muito importante, nunca havia pensado em trabalhá-lo em sala, especialmente com educação infantil. Achou a idéia de começar pela fauna muito oportuna por ser uma área de interesse das crianças. Ficou muito entusiasmada e disse que daria continuidade ao que eu 
havia começado, porém, antes de tudo, teria que conversar com a coordenação para tentar fazer disso um projeto mais formal.

\section{Atividade desenvolvida na SeeSaw Jardim de Infância}

\section{Por Andréa Maiolino}

Desenvolvi a atividade na sala em que trabalho regularmente como assistente, na escola See-Saw Jardim de Infância, uma escola particular, bilíngüe, localizada no bairro Real Parque / Morumbi, Zona Sul de São Paulo. A escola atende, em sua maioria, a classe média alta. A maioria dos alunos já tem três anos completos, os outros estarão completando até setembro. Achei que essa idéia de introduzir a África a partir dos animais seria bem interessante, pois as crianças adoram brincar com os bichos que existem na sala e estão sempre falando sobre animais, fazenda, etc.

Para o desenvolvimento do projeto, comecei apresentando algumas fotos de animais como leão, girafa e elefante. Perguntei se algum deles já tinha visto aqueles bichos em algum lugar e se eles sabiam onde os animais moravam. Algumas respostas interessantes apareceram: "Eles moram no zoológico! Eu vi eles lá!”; “Eu já vi no filme do Rei Leão”,’Eles moram na floresta".

Em seguida, falei para as crianças que aqueles animais eram originários da África, aproveitei a resposta sobre o filme Rei Leão, da Disney, para explicar que todo o filme se passa na África. Pela expressão de espanto das crianças, percebi que alguns conceitos como continente e país seriam um pouco difíceis para eles entenderem. Por isso, comecei a fazer algumas comparações com o Brasil. Primeiramente, mostrei um mapa do mundo e localizei o Brasil no continente Americano e alguns países africanos. Mostrei algumas fotos das florestas que existem no Brasil, alguns 
animais que vivem nessas florestas e apresentei também fotos da floresta e da savana africana e ainda de outros animais africanos. As crianças se interessaram bastante pelos animais que não são tão populares entre nós tais como: antilopes, palanca negra, cabras-de-leque, gnus, impalas, chitas, búfalos e pelo jacaré que, ao contrário dos outros animais, é bem popular entre as crianças porque elas gostam muito de uma música que fala do jacaré.

Continuando com as comparações entre Brasil e África, disse que em muitos paises deste continente, pessoas falam português como nós no Brasil. Como a escola é bilíngue, acrescentei que o inglês que nós também falamos, é falado nos EUA e na África do Sul. Completei dizendo que nos outros paises da África se falam outras linguas diferentes, assim como na América se falam outras linguas como o espanhol. Deste modo, encerrei a discussão inclusive porque comecei a perceber que todos esses conceitos como país, continente, diferentes línguas, que para nós, adultos, são óbvios, para as crianças, são abstratos demais. Percebi, neste momento, que, continuar falando sobre esses assuntos seria cansativo para eles. Apesar disso, acho que a discussão foi proveitosa e, de fato, foi uma breve introdução aos estudos afro-brasileiros e africanos. Mesmo que eles não tenham entendido cem por cento das informações apresentadas, tenho certeza de que eles aproveitaram a discussão e o momento de conversa.

Depois de toda essa discussão, propus à sala que fizéssemos um grande mapa da África, com todas as imagens estudadas no decorrer da discussão, para que esse mapa pudesse enfeitar a sala e, quem sabe até, promover novas conversas no decorrer do semestre. As crianças, é claro, adoraram a idéia. Já começaram a percorrer a sala em busca dos materiais necessários como cola, tesoura, lápis de cor, giz de cera, tinta e pincel.

As crianças se divertiram bastante nessa parte da atividade. Cortei a 
forma de um grande continente africano para ser a base do nosso trabalho. As crianças então espalharam as fotos e as imagens pelo mapa, desenharam e pintaram por cima ou preenchendo os espaços brancos dizendo o que estavam representando com o desenho. "Aqui vai ser a floresta", "Aqui é a casa do leão", etc. Ao final do trabalho, tínhamos um belo mapa da África bastante colorido e cheio de imagens significativas da região.

Considero que esse trabalho foi bem proveitoso. As crianças puderam se divertir e aprender bastante tanto na discussão em grupo quanto na parte artística da atividade. E, além disso, ainda tiveram a oportunidade começar a entrar em contato e entender o que são os continentes, países, línguas e culturas diferentes.

\section{Autoras}

\section{Andréa Mesquita Rampone}

Graduanda da Faculdade de Educação da Universidade de São Paulo Contato: andrea.rampone@usp.br

\section{Andréa Rigazzo Maiolino}

Graduanda da Faculdade de Educação da Universidade de São Paulo Contato: andrea.maiolino@usp.br 


\section{Como citar este depoimento:}

RAMPONE Andréa Mesquita e MAIOLINO Andréa Rigazzo. A África para crianças da educação infantil. Revista ACOALFAplp: Acolhendo a Alfabetização nos Países de Língua portuguesa, São Paulo, ano 3, n. 6, 2009. Disponível em: <http://www.acoalfaplp.net>. Publicado em: março 2009.

Recebido em julho de 2008/ Aprovado em agosto de 2008

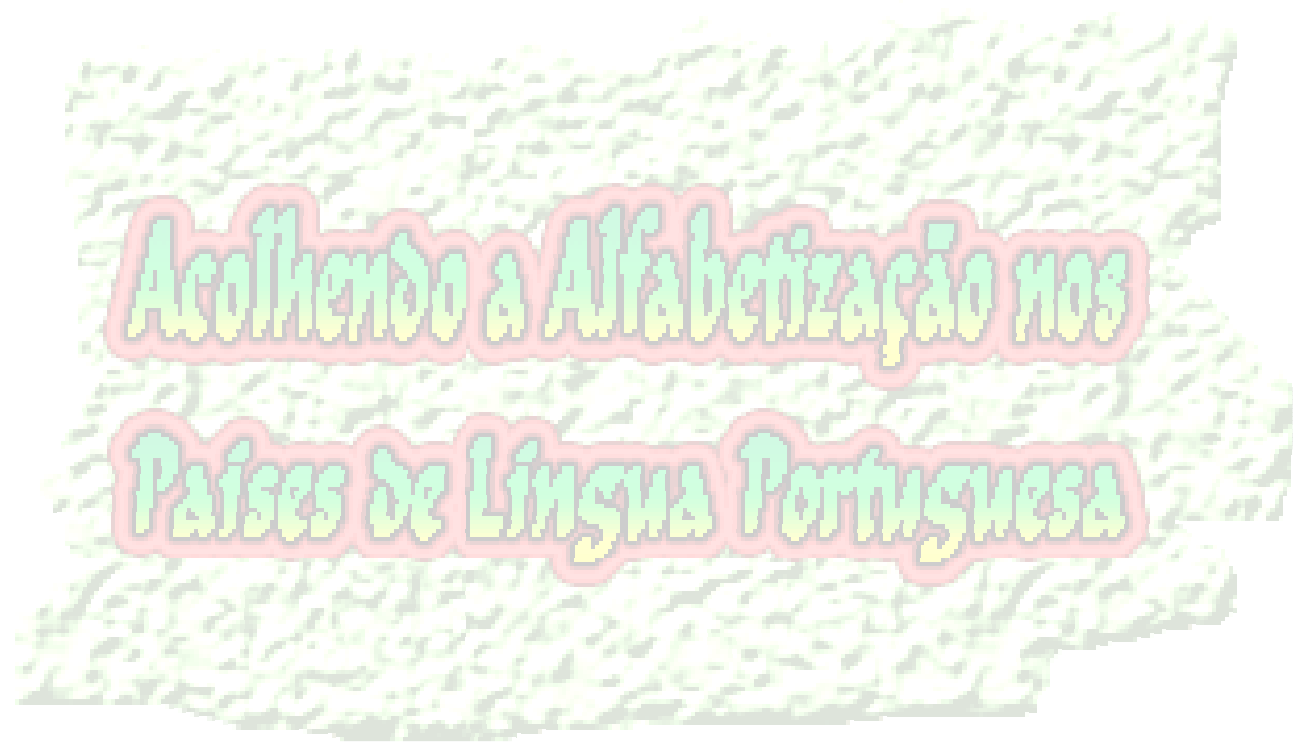

